\title{
Listerial Spontaneous Bacterial Peritonitis
}

Review began 08/01/2021
Review ended 02/07/2022
Published 02/09/2022
@ Copyright 2022
Samant et al. This is an open access article
distributed under the terms of the Creative
Commons Attribution License CC-BY 4.0.,
which permits unrestricted use, distribution,
and reproduction in any medium, provided
the original author and source are credited.

\author{
Samira Samant ${ }^{1}$, Bradley Uyemura ${ }^{1}$, Pandit Sarbagya ${ }^{1}$, Pinky Jha ${ }^{1}$ \\ 1. Internal Medicine, Medical College of Wisconsin, Milwaukee, USA \\ Corresponding author: Samira Samant, ssamant@mcw.edu
}

\begin{abstract}
Spontaneous bacterial peritonitis (SBP) is a severe complication of ascites often seen in advanced hepatic disease that is most commonly caused by Gram-negative bacilli. Here, we report a rare case of Listeria monocytogenes SBP, diagnosed by peritoneal fluid culture and responsive to ampicillin, in a patient with portal hypertension secondary to nodular regenerative hyperplasia. Because Listeria species are resistant to empiric SBP therapies and delays in treatment have been associated with increased mortality, they must be considered in high-risk patients.
\end{abstract}

Categories: Endocrinology/Diabetes/Metabolism, Internal Medicine, Infectious Disease

Keywords: spontaneous bacterial peritonitis, listeria monocytogenes, ascites, listeria sbp, corynebacterium

\section{Introduction}

Spontaneous bacterial peritonitis (SBP) is an infection of the ascitic fluid that arises without a definitive intra-abdominal source and is most commonly seen in advanced hepatic disease [1]. Crucial to the development of this infection is bacterial translocation; that is, the failure of containment of bacteria within the bowel that allows the passage of bacteria from the intestinal lumen to mesenteric lymph nodes, which subsequently affords the possibility of spread to the bloodstream or other extra-intestinal sites [2]. This translocation may be preceded by bacterial overgrowth associated with an impaired intestinal barrier, diminished immunologic defenses, or decreased bowel motility in cirrhotic patients. While some cases of SBP are associated with the development of acute septic shock, others may be asymptomatic; the latter is often identified when a patient with cirrhosis undergoes routine paracentesis [1].

A diagnosis of SBP must be made in the absence of any identifiable etiology of infection or secondary bacterial peritonitis, including gastrointestinal tract perforations, diverticulitis, cholecystitis, or appendicitis, and requires a sample of ascitic fluid [3]. A polymorphonuclear (PMN) count greater than 250 cells $/ \mathrm{mm}^{3}$ suggests SBP, and a positive ascitic fluid culture typically confirms the diagnosis [3].

The most common causative organisms in SBP tend to be Gram-negative bacilli; the three most common are Escherichia coli, Streptococcus, and Klebsiella species, although numerous other bacteria have been demonstrated to cause SBP at a much lower incidence [3]. Antibiotic treatment for SBP is designed with the causative predominance of coliform bacteria in mind. Third-generation cephalosporins are typically the antibiotics of choice, as they have a broad antibacterial coverage coupled with a good safety profile; cefotaxime is the most commonly used agent in this class [2]. Oral fluoroquinolones may also be used in patients not suffering from nausea or emesis, or in patients allergic to cephalosporins.

While a short or long course of antibiotics is typically sufficient to resolve the infection, occasionally these measures prove ineffective. In such cases, it is crucial to investigate further, as a less frequently implicated bacterium may be the underlying cause of SBP.

\section{Case Presentation}

Our patient was a 71-year-old female with a past medical history significant for hypertension, Crohn's disease, and non-cirrhotic portal hypertension with esophageal varices and ascites secondary to nodular regenerative hyperplasia, who presented with a chief complaint of rectal pain and abdominal distension. Her home medications were carvedilol, furosemide, spironolactone, infliximab, and famotidine. Her allergy history was significant for reactions to sulfa drugs and augmentin.

One month prior to this admission, she had been evaluated for a fever of unknown origin, with an extensive workup significant for a CT abdomen and pelvis showing colitis. While antibiotics proved ineffective, prednisone abated her fever. Shortly after steroid treatment, she developed worsening abdominal distension. Paracentesis removed 5.5 L of cloudy-yellow fluid containing an elevated white blood cell count of over 5000 cells $/ \mathrm{mm}^{3}$, with $86 \%$ PMNs. She was started on a ten-day course of cephalexin but nine days later was admitted for severe rectal pain and abdominal distension. Repeat paracentesis yielded $600 \mathrm{ml}$ of cloudy-yellow fluid with a white blood cell count of 2800 cells $/ \mathrm{mm}^{3}$, with $82 \%$ PMNs. Her white count was elevated from $7.6 \times 103 / \mu \mathrm{L}$ to $17 \times 103 / \mu \mathrm{L}$, but BMP and transaminases were unremarkable. A CT abdomen 


\section{Cureus}

and pelvis revealed cirrhotic changes, new left-sided pleural effusion, increased ascites, and a new $2.5 \mathrm{~cm}$ focus of air-fluid level contiguous with the posterior anus and extending to the gluteal cleft, suspicious for a perianal abscess (Figure 1). Biopsy of her liver revealed a few foci of alternating compressed and normal liver cell plates, suggestive of nodular regenerative hyperplasia; minimal foci of sinusoidal fibrosis; and minimal portal inflammation primarily consisting of mononuclear cells. Her ascitic fluid yielded Gram-positive rods, and the culture grew cephalexin-resistant Corynebacterium. The cephalexin was switched to vancomycin for more appropriate antimicrobial coverage, but she developed diarrhea. When trended, her improving erythrocyte sedimentation rate and C-reactive protein made a Crohn's flare unlikely. A C. difficile nucleic acid amplification test was positive, but she was found to be toxin-negative, suggesting antibiotic-induced diarrhea.

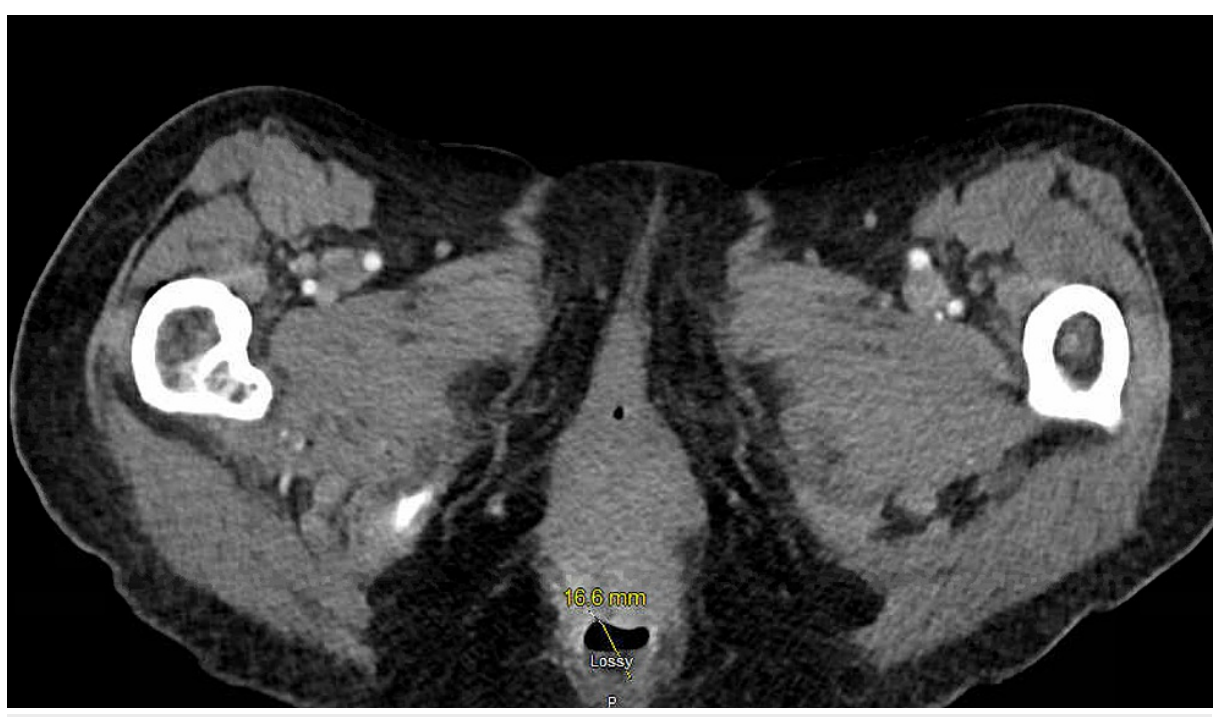

FIGURE 1: Perianal abscess identified on CT A/P

Given her recent CT A/P findings, infectious disease suspected the Corynebacterium was a contaminant from her perianal abscess; reevaluation of her ascitic culture revealed Listeria monocytogenes. A further, more detailed history-taking revealed that she owned a dairy farm, and her husband had recently suffered from a gastrointestinal illness. She likely contracted enteric Listeria that seeded her peritoneal fluid. Ampicillin was initiated, and repeat paracentesis showed a recovering white cell count, with negative Gram stain and culture. She was discharged on amoxicillin.

\section{Discussion}

Listeria is a Gram-positive rod that can be regularly isolated from soil, water, vegetation, and even asymptomatic humans [4]. Though rare cases of human infections by L. lvanovii and L. grayi have been reported, $L$. monocytogenes is the primary pathogen in humans $[5,6]$. Given that $L$. monocytogenes can thrive in a wide $\mathrm{pH}$ range and refrigerator temperatures, it has been associated with a variety of foodborne outbreaks including processed meats, soft cheeses, and raw produce [5,7-10].

Listeriosis typically manifests as self-limiting febrile gastroenteritis [11]. While less than $1 \%$ of reported cases of bacterial foodborne infections are attributed to Listeria, it can cause invasive diseases such as meningitis, meningoencephalitis, and bacteremia in susceptible individuals, with mortality rates as high as $20-30 \%[12,13]$. Populations that have been shown to be predisposed to Listeria infection include neonates, pregnant women, the elderly, and the immunocompromised [14-17]. Our patient had been receiving glucocorticoid therapy for the prior two months for her Crohn's disease prior to the transition to infliximab; notably, glucocorticoids have also been specifically associated with an increased risk of Listeriosis [18]. In addition, it has been shown that farm animals represent a reservoir for human L. monocytogenes infections [19].

Listeria was first described as a cause of SBP in 1977 [20], but has remained exceptionally rare. A literature review published in 2015 listed just 106 reported cases of Listeria SBP, with only 11 cases in the United States [21]. Instead, nearly $40 \%$ of cases have been reported in Spain, despite the fact that human listeriosis, in general, is not preferentially elevated in the region [22,23]. Though it is unclear why SBP secondary to Listeria is predominantly reported in Spain, it is speculated that cultural differences involving increased consumption of contaminated dairy products, produce, and processed meats could be contributing.

Empiric therapy for SBP generally involves third-generation cephalosporins, such as cefotaxime or ceftriaxone, given their historically good coverage of the most common pathogens, which include $E$. coli, 
Klebsiella pneumoniae, and pneumococci $[24,25]$. However, several reports have demonstrated failure rates of empiric cephalosporin treatment as high as $43 \%$ [26,27]. In fact, L. monocytogenes has consistently been reported to be intrinsically resistant to third-generation cephalosporins due to poor cephalosporin targetbinding [28]. As such, ampicillin with an aminoglycoside, if the toxicity profile allows, has been successfully used to treat SBP caused by L. monocytogenes [29]. Though the associated symptoms of Listeria peritonitis are largely indistinguishable from any other causes of SBP, delayed treatment from initial incorrect empiric antibiotic therapy has been associated with worse outcomes, with an overall mortality of $30 \%$ [23]. Thus, prompt evaluation of risk factors, geography, occupational exposures, and recent foodborne illnesses/outbreaks can be essential for suspecting Listeriosis and consequently adjusting empiric antibiotic therapy for L. monocytogenes coverage.

Because the cumulative recurrence rate at one year of SBP is nearly $70 \%$, prophylactic antibiotics are indicated [30]. While norfloxacin is typically used for SBP prophylaxis, it often does not provide coverage for L. monocytogenes. As such, amoxicillin or trimethoprim-sulfamethoxazole is recommended for patients recovering from Listeria SBP [31].

\section{Conclusions}

Listeria is an exceptionally rare cause of SBP. Its presentation closely mimics that of other pathogens, making the recognition of ascitic or blood cultures with Gram-positive rods crucial, along with the recognition of risk factors such as immunosuppression, exposure to farm animals or contaminated foods, and iron overload. Listeria must be considered as a potential causative organism in patients with SBP who are not responding to conventional therapy, especially if such risk factors are present. Because it is resistant to some cephalosporins, ampicillin - with an aminoglycoside if tolerated - is the treatment of choice. Following an initial episode of Listeria SBP, the recurrence rate is as high as $70 \%$ in one year; for this reason, prophylactic antibiotics are typically initiated as a preventative measure. Listeria frequently has innate fluoroquinolone resistance, making trimethoprim-sulfamethoxazole the prophylactic antibiotic of choice.

\section{Additional Information \\ Disclosures}

Human subjects: Consent was obtained or waived by all participants in this study. Conflicts of interest: In compliance with the ICMJE uniform disclosure form, all authors declare the following: Payment/services info: All authors have declared that no financial support was received from any organization for the submitted work. Financial relationships: All authors have declared that they have no financial relationships at present or within the previous three years with any organizations that might have an interest in the submitted work. Other relationships: All authors have declared that there are no other relationships or activities that could appear to have influenced the submitted work.

\section{References}

1. Alaniz C, Regal RE: Spontaneous bacterial peritonitis: a review of treatment options .P T. 2009, 34:204-10.

2. Koulaouzidis A, Bhat S, Karagiannidis A, Tan WC, Linaker BD: Spontaneous bacterial peritonitis. Postgrad Med J. 2007, 83:379-83. 10.1136/pgmj.2006.056168

3. Dever JB, Sheikh MY: Review article: spontaneous bacterial peritonitis--bacteriology, diagnosis, treatment, risk factors and prevention. Aliment Pharmacol Ther. 2015, 41:1116-31. 10.1111/apt.13172

4. Schlech WF 3rd, Schlech WF 4th, Haldane H, Mailman TL, Warhuus M, Crouse N, Haldane DJ: Does sporadic Listeria gastroenteritis exist? A 2-year population-based survey in Nova Scotia, Canada. Clin Infect Dis. 2005, 41:778-84. 10.1086/432724

5. Salimnia H, Patel D, Lephart PR, Fairfax MR, Chandrasekar PH: Listeria grayi: vancomycin-resistant, grampositive rod causing bacteremia in a stem cell transplant recipient. Transpl Infect Dis. 2010, 12:526-8. 10.1111/j.1399-3062.2010.00539.x

6. Guillet C, Join-Lambert O, Le Monnier A, et al.: Human listeriosis caused by Listeria ivanovii . Emerg Infect Dis. 2010, 16:136-8. 10.3201/eid1601.091155

7. Self JL, Conrad A, Stroika S, et al.: Multistate outbreak of listeriosis associated with packaged leafy green salads, United States and Canada, 2015-2016. Emerg Infect Dis. 2019, 25:1461-8. 10.3201/eid2508.180761

8. McCollum JT, Cronquist AB, Silk BJ, et al.: Multistate outbreak of listeriosis associated with cantaloupe. N Engl J Med. 2013, 369:944-53. 10.1056/NEJMoa1215837

9. Jackson KA, Biggerstaff M, Tobin-D'Angelo M, et al.: Multistate outbreak of Listeria monocytogenes associated with Mexican-style cheese made from pasteurized milk among pregnant, Hispanic women. J Food Prot. 2011, 74:949-53. 10.4315/0362-028X.JFP-10-536

10. Cartwright EJ, Jackson KA, Johnson SD, Graves LM, Silk BJ, Mahon BE: Listeriosis outbreaks and associated food vehicles, United States, 1998-2008. Emerg Infect Dis. 2013, 19:1-9; quiz 184. 10.3201/eid1901.120393

11. Ooi ST, Lorber B: Gastroenteritis due to Listeria monocytogenes. Clin Infect Dis. 2005, 40:1327-32. $10.1086 / 429324$

12. Scallan E, Hoekstra RM, Angulo FJ, et al.: Foodborne illness acquired in the United States--major pathogens . Emerg Infect Dis. 2011, 17:7-15. 10.3201/eid1701.p11101

13. de Noordhout CM, Devleesschauwer B, Angulo FJ, et al.: The global burden of listeriosis: a systematic review and meta-analysis. Lancet Infect Dis. 2014, 14:1073-82. 10.1016/S1473-3099(14)70870-9

14. Silk BJ, Date KA, Jackson KA, et al.: Invasive listeriosis in the Foodborne Diseases Active Surveillance Network (FoodNet), 2004-2009: further targeted prevention needed for higher-risk groups. Clin Infect Dis. 
2012, 54 Suppl 5:S396-404. 10.1093/cid/cis268

15. Goulet V, Hebert M, Hedberg C, Laurent E, Vaillant V, De Valk H, Desenclos JC: Incidence of listeriosis and related mortality among groups at risk of acquiring listeriosis. Clin Infect Dis. 2012, 54:652-60. 10.1093/cid/cir902

16. Büla CJ, Bille J, Glauser MP: An epidemic of food-borne listeriosis in western Switzerland: description of 57 cases involving adults. Clin Infect Dis. 1995, 20:66-72. 10.1093/clinids/20.1.66

17. Skogberg K, Syrjänen J, Jahkola M, et al.: Clinical presentation and outcome of listeriosis in patients with and without immunosuppressive therapy. Clin Infect Dis. 1992, 14:815-21. 10.1093/clinids/14.4.815

18. Anaissie E, Kontoyiannis DP, Kantarjian H, Elting L, Robertson LE, Keating M: Listeriosis in patients with chronic lymphocytic leukemia who were treated with fludarabine and prednisone. Ann Intern Med. 1992, 117:466-9. 10.7326/0003-4819-117-6-466

19. Nightingale KK, Schukken YH, Nightingale CR, et al.: Ecology and transmission of Listeria monocytogenes infecting ruminants and in the farm environment. Appl Environ Microbiol. 2004, 70:4458-67. 10.1128/AEM.70.8.4458-4467.2004

20. Rheingold OJ, Chiprut RO, Dickinson GM, Schiff ER: Spontaneous peritonitis of cirrhosis due to Listeria monocytogenes. Ann Intern Med. 1977, 87:455-6. 10.7326/0003-4819-87-4-455_2

21. How J, Azar MM, Meyer JP: Are nectarines to blame? A case report and literature review of spontaneous bacterial peritonitis due to Listeria monocytogenes. Conn Med. 2015, 79:31-6.

22. Denny J, McLauchlin J: Human Listeria monocytogenes infections in Europe--an opportunity for improved European surveillance. Euro Surveill. 2008, 13:

23. Liatsos GD, Thanellas S, Pirounaki M, Ketikoglou I, Moulakakis A: Listeria monocytogenes peritonitis: presentation, clinical features, treatment, and outcome. Scand J Gastroenterol. 2012, 47:1129-40. 10.3109/00365521.2012.704935

24. Felisart J, Rimola A, Arroyo V, Perez-Ayuso RM, Quintero E, Gines P, Rodes J: Cefotaxime is more effective than is ampicillin-tobramycin in cirrhotics with severe infections. Hepatology. 1985, 5:457-62. 10.1002/hep.1840050319

25. Runyon BA: Management of adult patients with ascites due to cirrhosis: an update . Hepatology. 2009, 49:2087-107. 10.1002/hep.22853

26. Angeloni S, Leboffe C, Parente A, Venditti M, Giordano A, Merli M, Riggio O: Efficacy of current guidelines for the treatment of spontaneous bacterial peritonitis in the clinical practice. World J Gastroenterol. 2008, 14:2757-62. 10.3748/wjg.14.2757

27. Novovic S, Semb S, Olsen H, Moser C, Knudsen JD, Homann C: First-line treatment with cephalosporins in spontaneous bacterial peritonitis provides poor antibiotic coverage. Scand J Gastroenterol. 2012, 47:212-6. 10.3109/00365521.2011.645502

28. Krawczyk-Balska A, Markiewicz Z: The intrinsic cephalosporin resistome of Listeria monocytogenes in the context of stress response, gene regulation, pathogenesis and therapeutics. J Appl Microbiol. 2016, 120:25165. 10.1111/jam.12989

29. Shaikh B, Pathak R, Mainali NR, Gupta S: Listeria monocytogenes as a cause of spontaneous bacterial peritonitis: a rare entity. J Community Hosp Intern Med Perspect. 2015, 5:26153. 10.3402/jchimp.v5.26153

30. Cardoso C, Cremers I, Oliveira AP: Spontaneous bacterial peritonitis caused by Listeria monocytogenes: a case report and literature review. Ann Hepatol. 2012, 11:955-7. 10.1016/S1665-2681(19)31425-5

31. Runyon BA: Monomicrobial nonneutrocytic bacterascites: a variant of spontaneous bacterial peritonitis . Hepatology. 1990, 12:710-5. 10.1002/hep.1840120415 